\title{
The Structural Stability of Soft Magnetic Fe-Co-Zr-W-B Metallic Glasses Investigated by the in-situ X-ray Diffraction
}

\author{
S. Michalik ${ }^{a, b}$, J. BednarciK ${ }^{c}$, P. PAWlik ${ }^{d}$, R. Matija ${ }^{e}$ And P. SovaK ${ }^{b, *}$ \\ ${ }^{a}$ Institute of Physics of the ASCR, v.v.i., Na Slovance 2, 18221 Praha 8, Czech Republic \\ ${ }^{b}$ Institute of Physics, Park Angelinum 9, 04154 Kosice, Slovakia \\ ${ }^{c}$ Deutsches Elektronen-Synchrotron, Notkestrasse 85, 22607 Hamburg, Germany \\ ${ }^{d}$ Institute of Physics, Czestochowa University of Technology, Al. A. Krajowej 19, 42-200 Czestochowa, Poland \\ ${ }^{e}$ Faculty of manufacturing technologies of Technical University of Kosice with a seat in Presov, Bayerova 1,08001 \\ Presov, Slovakia \\ The atomic structure of as-prepared $\mathrm{Fe}_{61} \mathrm{Co}_{(14-x)} \mathrm{Zr}_{5} \mathrm{~W}_{x} \mathrm{~B}_{20}(x=1,2$ and 4$)$ ribbon samples and their thermal \\ stability were investigated by in-situ high-energy X-ray diffraction experiments. It was observed that higher W \\ concentration causes the tiny shift of the main peak of the reduced atomic pair distribution function to higher \\ values of interatomic distances and increases the coefficient of volume thermal expansion. The crystallization \\ process occurs in two steps and is qualitatively the same for all studied specimens. Firstly the $\mathrm{Fe}_{23} \mathrm{~B}_{6}$ phase is \\ created and later is transformed to other types of borides together with the creation of a Fe-based phase.
}

DOI: 10.12693 /APhysPolA.126.66

PACS: 61.05.cp, 61.43.Dq

\section{Introduction}

It has previously been shown that Fe-Co-Zr-W-B alloys are suitable representatives of iron-based metallic glasses with good soft magnetic properties demonstrated by the low coercivity $H_{c}=1.4 \pm 0.5 \mathrm{~A} / \mathrm{m}$, the relatively high magnetic saturation $\mu_{0} M_{s}=0.8 \mathrm{~T}$ [1] and the Curie temperature $T_{C} \sim 300{ }^{\circ} \mathrm{C}$ [2]. In this work the authors present the complete structural study of asprepared glassy ribbons $\mathrm{Fe}_{61} \mathrm{Co}_{(14-x)} \mathrm{Zr}_{5} \mathrm{~W}_{x} \mathrm{~B}_{20}(x=1$, 2 and 4 ) and their structural evolution during thermal loading using the high energy X-ray diffraction (XRD).

\section{Experimental}

Ribbon samples of the composition $\mathrm{Fe}_{61} \mathrm{Co}_{(14-x)} \mathrm{Zr}_{5} \mathrm{~B}_{20} \mathrm{~W}_{x}$ with $x=1,2$ and 4 were prepared by a melt spinning technique. The high-energy X-ray diffraction experiments were carried out at the beamline BW5 at HASYLAB/DESY (Hamburg, Germany) using X-rays of the wavelength $0.1239 \AA$. The heating of the samples was performed from $20{ }^{\circ} \mathrm{C}$ to $200{ }^{\circ} \mathrm{C}$ and from $200{ }^{\circ} \mathrm{C}$ to $800{ }^{\circ} \mathrm{C}$ with the heating rate of $50{ }^{\circ} \mathrm{C} / \mathrm{min}$ and $5{ }^{\circ} \mathrm{C} / \mathrm{min}$, respectively. Diffraction patterns were recorded by a $2 \mathrm{D}$ Mar345 image plate detector placed orthogonally to the incoming beam. The obtained 2D XRD data were radially integrated into the reciprocal $Q$-space using the FIT2D program [3]. Then the structural factor $S(Q)$ was calculated applying the Faber-Ziman formula [4].

*corresponding author; e-mail: pavol.sovak@upjs.sk

\section{Results}

Figure 1 shows structural factors $S(Q)$ s of the asprepared alloys. The $S(Q)$ s are dominated by two broad maxima followed by low intensive oscillations visible up to $17 \AA^{-1}$ suggesting the fully amorphous character. However, the detailed inspection of $S(Q)_{x=2}$ revealed almost undetectable Bragg peaks (marked by arrows) proving the tiny portion of a crystalline phase inside the sample $x=2$.

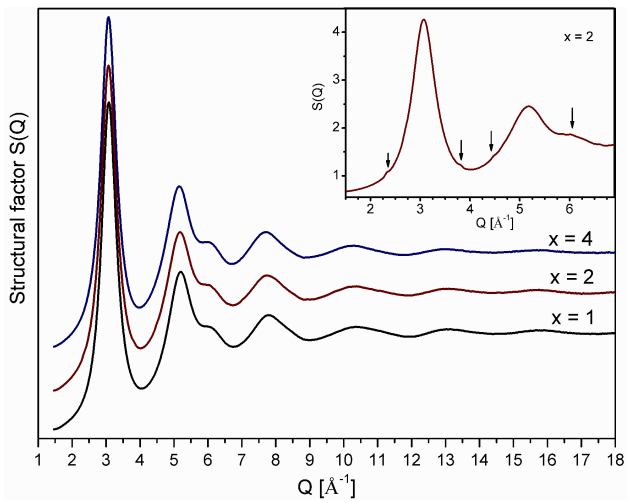

Fig. 1. $S(Q) \mathrm{s}$ of the as-prepared $\mathrm{Fe}_{61} \mathrm{Co}_{(14-x)} \mathrm{Zr}_{5} \mathrm{~B}_{20} \mathrm{~W}_{x}$ samples. Insert at right upper corner shows in detail $S(Q)_{x=2}$.

In order to obtain additional information about the local atomic arrangement in as-prepared samples, the total reduced atomic pair distribution function $D(r)$ was calculated from the structural factor $S(Q)$ applying a sine form of the Fourier transformation. The $D(r) \mathrm{s}$ of investigated samples are similar and are practically undistin- 
guishable at the high $r$ interval, see Fig. 2. Small differences are mainly observable on the first and second maxima, which contain information about the average closest atomic order around an average atom. The insert of Fig. 2 shows in detail the first maximum and reveals its strongly asymmetric shape suggesting the contribution from at least two subshells. The first subshell could come from atomic pairs of $\mathrm{Fe}-\mathrm{Fe}$ and $\mathrm{Fe}-\mathrm{Co}$, the second one from $\mathrm{Fe}-\mathrm{W}$ and the third one from $\mathrm{Fe}-\mathrm{Zr}$ pairs. Additionally, it is seen that the central maximum position slightly shifts from $2.565 \AA$ to $2.580 \AA$ with the increasing $\mathrm{W}$ amount as the result of the replacement of smaller $\mathrm{Co}$ atoms $\left(r_{\mathrm{Co}}=1.253 \AA\right)$ by greater $\mathrm{W}$ ones $\left(r_{\mathrm{W}}=1.37 \AA\right)$.

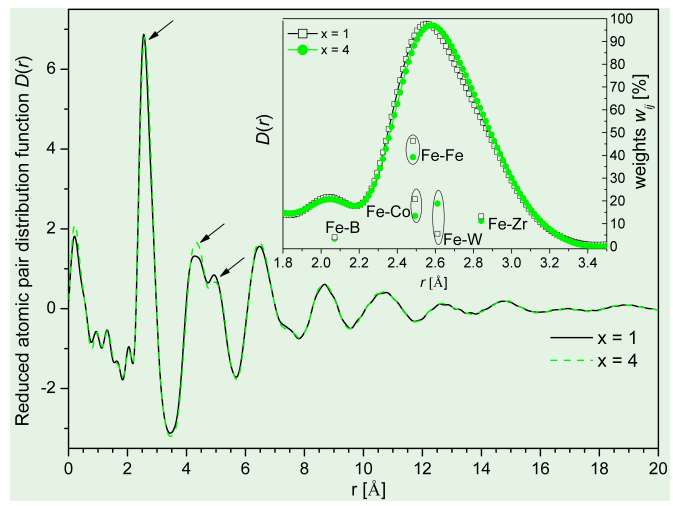

Fig. 2. $D(r) \mathrm{s}$ of as-prepared $\mathrm{Fe}_{61} \mathrm{Co}_{(14-x)} \mathrm{Zr}_{5} \mathrm{~B}_{20} \mathrm{~W}_{x}$ samples for $x=1$ and 4 . Arrows sign changes in $D(r)$ s. The first maximum of $D(r)$ is shown together with bond lengths and corresponding weights of the most pronounced atomic pairs.

Diffraction profiles taken during heating of the $\mathrm{Fe}_{61} \mathrm{Co}_{13} \mathrm{Zr}_{5} \mathrm{~B}_{20} \mathrm{~W}_{1}$ alloy are displayed in Fig. 3. Firstly, XRD profiles seem to be without any noticeable modification, suggesting that the sample persists in its original (amorphous) state. However, marginal shifts of the main diffraction peak were detected and used for the extraction of the coefficient of volume thermal expansion $\alpha_{t h}$, following Yavari approach [5]. The values of $\alpha_{t h}$ are $(3.00 \pm 0.06) \times 10^{-5} 1 /{ }^{\circ} \mathrm{C},(3.40 \pm 0.10) \times 10^{-5} 1 /{ }^{\circ} \mathrm{C}$ and $(4.15 \pm 0.09) \times 10^{-5} 1 /{ }^{\circ} \mathrm{C}$ for the samples with $x=1$, 2 and 4 . Then, at certain point, Bragg peaks are appearing to indicate the beginning of the first crystallization. Formed Bragg peaks are indexed as the cubic phase $\mathrm{Fe}_{23} \mathrm{~B}_{6}$. It is worthnoting that low intensive Bragg peaks presented in the as-prepared $\mathrm{Fe}_{61} \mathrm{Co}_{12} \mathrm{Zr}_{5} \mathrm{~W}_{2} \mathrm{~B}_{20}$ alloy could be index as the $\mathrm{Fe}_{73} \mathrm{~B}_{6}$ phase as well. Observed first crystallization temperatures $552{ }^{\circ} \mathrm{C}(x=1), 527{ }^{\circ} \mathrm{C}$ $(x=2)$ and $564{ }^{\circ} \mathrm{C}(x=4)$ are in quite good accordance with calorimetric results presented in previous work [2] with the exception of the sample $\mathrm{Fe}_{61} \mathrm{Co}_{12} \mathrm{Zr}_{5} \mathrm{~W}_{2} \mathrm{~B}_{20}$. This discrepancy is understandable in view of the fact, that in our case, the as-prepared $\mathrm{Fe}_{61} \mathrm{Co}_{12} \mathrm{Zr}_{5} \mathrm{~W}_{2} \mathrm{~B}_{20}$ sample is not fully amorphous and contains the subtle fraction of the crystalline $\mathrm{Fe}_{23} \mathrm{~B}_{6}$ phase which serves as crystalline seeds. Further analysis of XRD patterns taken at higher temperatures hints that the $\mathrm{Fe}_{23} \mathrm{~B}_{6}$ phase formed during the first crystallization is not stable and is transformed to other borides. Additionally, the phase analysis during second crystallization confirmed formation of a cubic similar Fe phase and suggested the presence of the $\mathrm{Fe}_{3} \mathrm{Zr}$ phase.

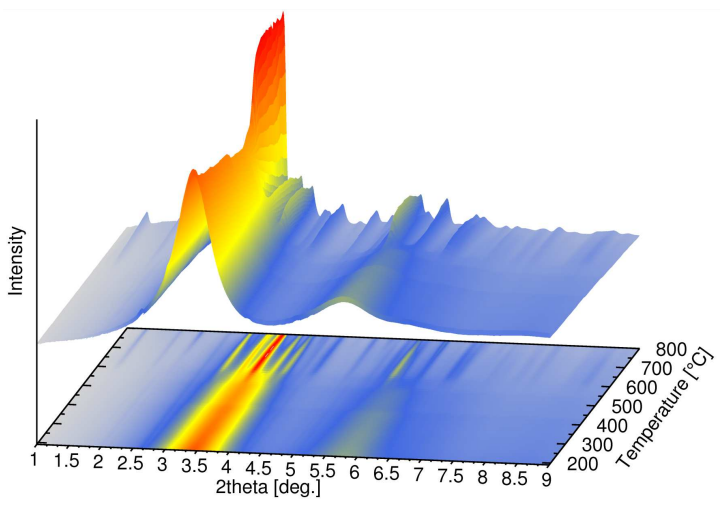

Fig. 3. Series of XRD patterns acquired during the constant-rate heating of the $\mathrm{Fe}_{61} \mathrm{Co}_{13} \mathrm{Zr}_{5} \mathrm{~B}_{20} \mathrm{~W}_{1}$.

\section{Conclusions}

The analysis of $D(r) \mathrm{s}$ of as-prepared ribbons $\mathrm{Fe}_{61} \mathrm{Co}_{(14-x)} \mathrm{Zr}_{5} \mathrm{~B}_{20} \mathrm{~W}_{x}(x=1,2$ and 4$)$ showed that the increase of $\mathrm{W}$ concentration slightly shifted the position of the peak corresponding to the first coordination shell, to higher $r$ values. No obvious changes of $D(r)$ s were observed above $6 \AA$. The $\alpha_{t h}$ coefficient increased with higher W concentration. All three samples proceeded from the as-prepared state to the final crystalline one in a similar way.

\section{Acknowledgments}

DESY is acknowledged for the technical support during experiments. This work was supported by the EC's Seventh Framework Programme under grant agreement $\mathrm{n}^{\circ}$ 312284. S.M. was supported by the Ministry of Education of the Czech Republic (ECOP program n. cz.1.07/2.3.00/30.0057). P.S. thanks for the support of the Slovak Grant Agency for Science n. 1/0148/12.

\section{References}

[1] P. Pawlik, H.A. Davies, M.R.J. Gibbs, Appl. Phys. Lett. 83, 2775 (2003).

[2] P. Pawlik, K. Pawlik, H.A. Davies, J.J. Wyslocki, W. Kaszuwara, M. Leonowicz, Journal of Magnetism and Magnetic Materials 304, e733 (2006).

[3] A.P. Hammersley, S.O. Svensson, M. Hanfland, A.N. Fitch, D. Hausermann, High. Press. Res. 14, 235 (1996).

[4] T. Egami and S.J. Billinge, Underneath the Bragg Peaks: Structural Analysis of Complex Materials Pergamon, Oxford 2003.

[5] A. Yavari, A. Moulec, A. Inoue, N. Nishiyama, N. Lupu, E. Matsubara, W.J. Botta, G. Vaughan, M. Di Michiel, A. Kvick Acta Materialia 53, 1611 (2005). 